\title{
PENGARUH PERILAKU INDIVIDU TERHADAP PELAKSANAAN KESEHATAN DAN KESELAMATAN KERJA DI PT. XXX INDONESIA
}

\author{
${ }^{1}$ Wanta \\ ${ }^{2}$ Rohendi \\ ${ }^{3}$ Aji Tuhagana \\ ${ }^{1}$ Jurusan Manajemen Fakultas Ekonomi dan Bisnis \\ Universitas Buana Perjuangan Karawang \\ Email: wanta@ubpkarawang.ac.id \\ ${ }^{2}$ Jurusan Manajemen Fakultas Ekonomi dan Bisnis \\ Universitas Buana Perjuangan Karawang \\ Email: mn15.rohendi@mhs.ubpkarawang.ac.id \\ ${ }^{3}$ Jurusan Manajemen Fakultas Ekonomi dan Bisnis \\ Universitas Buana Perjuangan Karawang \\ Email: aji.tuhagana@ubpkarawang.ac.id
}

\begin{abstract}
ABSTRAK
Penelitian dilakukan di PT. XXX Indonesia Jl. Maligi VIII Lot S-2 Kawasan Industri KIIC Desa Margakaya Kecamatan Telukjambe Barat Kabupaten Karawang Propinsi Jawa Barat. Penelitian ini bertujuan untuk mengetahui, menganalisis dan menjelaskan pengaruh perilaku individu terhadap keselamatan dan kesehatan kerja di PT. XXX Indonesia. Alat analisis yang digunakan uji validitas, uji reliabilitas, analisis korelasi, analisis regresi dan koefisien determinasi.

Hasil analisis koefisien korelasi antara perilaku individu dengan kesehatan dan keselamatan kerja diperoleh nilai sebesar 0,382 $(\mathrm{r} \neq 0)$ dengan tingkat signifikansi sebesar 0,000 , hal ini menunjukan bahwa terdapat hubungan positif rendah antara perilaku individu dengan kesehatan dan keselamatan kerja. Hasil analisis koefisien determinasi perilaku individu terhadap kesehatan dan keselamatan kerja diperoleh nilai sebesar 0,146 dengan tingkat signifikansi sebesar 0,000. Hal ini menunjukan bahwa terdapat pengaruh perilaku individu terhadap kesehatan dan keselamatan kerja sebesar $14,60 \%$ dan sisanya sebesar $85,40 \%$ dipengaruhi oleh factor lain yang tidak diteliti.
\end{abstract}

Kata kunci: Perilaku Individu, Kesehatan dan Keselamatan Kerja

\begin{abstract}
The study was conducted at PT. XXX Indonesia Jl. Maligi VIII Lot S-2 KIIC Industrial Estate Margakaya Village, Telukjambe Barat District, Karawang Regency, West Java Province. This study aims to determine, analyze and explain the effect of individual behavior on occupational safety and health at PT. XXX Indonesia. The analytical tool used is validity test, reliability test, correlation analysis, regression analysis and coefficient of determination.
\end{abstract}

The results of the correlation coefficient analysis between individual behavior with occupational health and safety obtained a value of $0.382(r \neq 0)$ with a significance level 
of 0,000, this shows that there is a low positive relationship between individual behavior with health and safety. The results of the analysis of the coefficient of determination of individual behavior towards health and safety obtained a value of 0.146 with a significance level of 0.000. This shows that there is an influence of individual behavior on occupational health and safety by $14.60 \%$ and the remaining $85.40 \%$ is influenced by other factors not examined.

Keywords: individual behavior, occupational health and safety

\section{PENDAHULUAN}

Menurut data dari Dinas Tenaga Kerja dan Transmigrasi UPTD Pengawasan Ketenagakerjan Wilayah II periode Januari 2018 sampai dengan Desember 2018, kasus kecelakaan kerja untuk Wilayah Kabupaten Karawang tercatat sebanyak 2.854 kasus, dimana terdapat 2.110 korban berjenis kelamin laki-laki dan 744 korban berjenis kelamin perempuan, dengan jumlah korbanmeninggal dunia sebanyak 21 orang, cacat sebanyak 5 orang, dan sembuh kembali dari penyakitnya sebanyak 2.828 orang.

Menurut data histori kecelakaan kerja yang tercatat oleh Departemen ISO \& Safety PT. XXX Indonesia di tahun 2018 terdapat 4 kasus kecelakaan kerja yang terjadi di eksternal perusahaan (pada saat berangkat dan pulang kerja).

Berdasarkan dari data tersebut terindikasi bahwa perilaku para tenaga kerja dalam melindungi dirinya melalio alat pelindung diri ditempat kerja masih sangat perlu ditingkatkan guna mengurangi jumlah resiko terjadinya angka kecelakaan kerja.

Perumusan masalah dalam penelititan ini adalah:

1. Bagaimana perilaku individu di PT. XXX Indonesia?

2. Bagaimana pelaksanaan sistem keselamatan dan kesehatan kerja di PT. XXX Indonesia?

3. Bagaimana pengaruh perilaku individu terhadap keselamatan dan kesehatan kerja di PT. XXX Indonesia?

Tujuan khusus penelitian ini adalah: 
1. Untuk mengetahui, menganalisis dan menjelaskan perilaku individu di PT. XXX Indonesia.

2. Untuk mengetahui, menganalisis dan menjelaskan sistem keselamatan dan kesehatan kerja di PT. XXX Indonesia.

3. Untuk mengetahui, menganalisis dan menjelaskan pengaruh perilaku individu terhadap keselamatan dan kesehatan kerja di PT. XXX Indonesia.

Zhu (2013:23) mengemukakan bahwa perilaku individu dari karyawan sebagai serangkaian reaksi dinamis karyawan, sebagai anggota organisasi, untuk internal dan merangsang lingkungan eksternal (the individual behavior of the employee as a series of dynamic reactions of the employee, as a member of the organization, to the internal and the external environmental stimulate).

Menurut Miftah Thoha (2011:30) perilaku individu adalah fungsi dari interaksi antara person atau individu dengan lingkungannya. Codreanu (2010:51) mengatakan bahwa perilaku individu digambarkan oleh serangkaian tindakan dilakukan dalam suatu lingkungan tertentu (individual behavior is described by a set of actions undertaken in a given environment).

Menurut Sedarmayanti (2017:133) pengertian keselamatan dan kesehatan kerja (K3) dapat ditinjau dari dua aspek, yakni aspek filosofis dan teknis". Secara filosofis, "keselamatan dan kesehatan kerja adalah konsep berpikir dan upaya nyata untuk menjamin kelestarian tenaga kerja pada khususnya dan setiap insan pada umumnya, beserta hasil karya dan budayanya dalam upaya menuju masyarakat adil, makmur, dan sejahtera.

Menurut Kuswana (2014:22) keselamatan dan kesehatan kerja adalah upaya atau pemikiran serta penerapannya yang ditujukan untuk menjamin keutuhan dan kesempurnaan baik jasmaniah maupun rohaniah tenaga kerja khususnya dan manusia pada umumnya, hasil karya dan budaya, untuk meningkatkan kesejahteraan tenaga kerja. 
Menurut Dewi Hanggraeni (2012:171) keselamatan dan kesehatan kerja adalah suatu sistem yang bertujuan melakukan pencegahan terhadap kemungkinan timbulnya kecelakaan yang diakibatkan oleh aktivitas kerja dan juga pencegahan akan timbulnya penyakit yang diakibatkan oleh hubungan kerja didalam lingkungan kerja para karyawan.

\section{METODE PENELITIAN}

\section{Jenis Penelitian}

Metode penelitian yang digunakan oleh peneliti adalah jenis penelitian descriptive survey dan explanatory atau verifikatif survey. Descriptive survey adalah survey untuk menggambarkan mengenai keadaan masing-masing variabel (variabel mandiri). Explanatory atau verifikatif survey adalah survey untuk menggambarkan asosiasi, hubungan ataupun pengaruh variabel independen terhadap variabel dependen. Pengertian asosiatif menurut Sugiyono (2012:55) adalah "suatu pertanyaan penelitian yang bersifat menyatakan hubungan antara dua variabel atau lebih".

\section{Waktu dan Tempat Penelitian}

Penelitian ini akan dilaksanakan selama 4 bulan, mulai dari bulan Maret sampai dengan Agustus 2019. Tempat penelitian ini dilaksanakan diperusahaan manufactur otomotif produksi spare part kendaraan roda dua dan empat yakni di PT. XXX Indonesia yang beralamat di Jl. Maligi VIII Lot S-2 Kawasan Industri KIIC Desa Margakaya Kecamatan Telukjambe Barat Kabupaten Karawang Propinsi Jawa Barat.

\section{Target / Subjek Penelitian}

Data yang digunakan adalah data primer dan data sekunder. Populasi sebanyak 110 orang yang terdapat pada Departemen Production 1 PT. XXX Indonesia. Teknik sampling yang digunakan adalah simple random sampling, sampel penelitian ini merujuk kepada rumus Isaac dan Michael dengan taraf kesalahan 5\% sehingga diperoleh sampel sebanyak 86 responden. 


\section{Prosedur Penelitian}

1. Penelitian ini berawal dari pendahuluan yang memuat latar belakang tentang adanya fenomena sehingga dilakukan sebuah penelitian. Dari fenomena permasalahan ini dibuat beberapa identifikasi masalah dan rumusan masalah, kemudian digambarkan dalam sebuah kerangka pemikiran dan ditentukan hipotesis penelitiannya.

2. Peneliti membuat desain penelitian bertujuan untuk membuat alur penelitian setelah didapatkannya sebuah fenomena permasalahan yang akan diteliti.

3. Peneliti menentukan sampel dari populasi objek penelitian untuk dijadikan responden dan meminta untuk mengisi kuisioner yang sudah disusun dioperasionalisasi variabel penelitian dan dikumpulkan kembali data hasil jawaban kuisioner dari responden tersebut.

4. Peneliti melakukan analisis terhadap data yang sudah terkumpul tersebut dengan menguji validitas, reliabilitas. Apabila hasilnya baik, maka dilanjutkan ke analisis selanjutnya yaitu analisis korelasi dan koefisien determinasi.

5. Peneliti membuat pembahasan dan kesimpulan dari hasil analisis tersebut dan sekaligus untuk menjawab dari rumusan masalah yang peneliti tuliskan diawal penelitian.

\section{Data, Instrumen, dan Teknik Pengumpulan Data}

Teknik pengumpulan data melalui penelitian lapangan (field research) yang merupakan cara untuk memperoleh data primer yang secara langsung dengan melibatkan pihak responden yang dijadikan sampel dalam penelitian. Peneliti melakukan pengamatan langsung pada objek yang akan diteliti sehingga diperoleh gambaran yang jelas mengenai permasalahan yang dihadapi sehingga dapat menjadi referensi untuk dijadikan penelitian. Selanjutnya peneliti melakukan pengumpulan data dengan cara menyebarkan kuisioner (daftar pertanyaan) kepada responden yang dijadikan sebagai sampel penelitian.

\section{Teknik Analisis Data}


Teknik analisis data yang digunakan dalam penelitian ini adalah teknik skala (skala likert), analisis rentang skala, transformasi data, uji validitas, uji reliabilitas, uji korelasi dan uji koefisien determinasi.

\section{HASIL PENELITIAN DAN PEMBAHASAN}

\section{Hasil Penelitian}

1. Persepsi Responden terhadap Perilaku Individu di PT. XXX Indonesia.

Tabel 4.1

Persepsi Responden terhadap Perilaku Individu

\begin{tabular}{|c|c|c|}
\hline No & Item Pernyataan & Skor \\
\hline 1 & $\begin{array}{l}\text { Faktor usia sangat berpengaruh terhadap konsentrasi } \\
\text { pada saat bekerja }\end{array}$ & 285 \\
\hline 2 & $\begin{array}{l}\text { Faktor usia sangat berpengaruh terhadap ketelitian } \\
\text { pada saat bekerja }\end{array}$ & 291 \\
\hline 3 & $\begin{array}{l}\text { Pekerja laki-laki cenderung kurang hati-hati dalam } \\
\text { bekerja }\end{array}$ & 221 \\
\hline 4 & $\begin{array}{l}\text { Pekerja perempuan cenderung hati-hati dalam } \\
\text { bekerja }\end{array}$ & 292 \\
\hline 5 & $\begin{array}{l}\text { Pekerja yang sudah menikah cenderung mematuhi } \\
\text { aturan kerja }\end{array}$ & 297 \\
\hline 6 & $\begin{array}{l}\text { Pekerja yang belum menikah cenderung kurang } \\
\text { mematuhi aturan kerja }\end{array}$ & 225 \\
\hline 7 & $\begin{array}{l}\text { Pekerja yang masa kerjanya diatas } 5 \text { tahun } \\
\text { mengalami penurunan semangat kerja }\end{array}$ & 221 \\
\hline 8 & $\begin{array}{l}\text { Saya memiliki kemampuan yang baik dalam } \\
\text { penyelesaian tugas }\end{array}$ & 333 \\
\hline 9 & $\begin{array}{l}\text { Saya bekerja sesuai dengan kemampuan pekerjaan } \\
\text { yang saya kuasai }\end{array}$ & 349 \\
\hline 10 & $\begin{array}{l}\text { Kemampuan intelektual yang tinggi dapat } \\
\text { meningkatkan kehati-hatian dalam bekerja }\end{array}$ & 329 \\
\hline 11 & $\begin{array}{l}\text { Kemampuan fisik sangat membantu terhadap } \\
\text { penyelesaian pekerjaan }\end{array}$ & 346 \\
\hline 12 & $\begin{array}{l}\text { Pekerjaan yang saya laksanakan sesuai dengan } \\
\text { pendidikan saya }\end{array}$ & 287 \\
\hline 13 & $\begin{array}{l}\text { Pelatihan yang saya pernah ikuti menjadikan saya } \\
\text { paham akan sikap kerja yang baik }\end{array}$ & 358 \\
\hline 14 & $\begin{array}{l}\text { Pengalaman yang saya punya membuat saya bekerja } \\
\text { dengan hati-hati }\end{array}$ & 367 \\
\hline 15 & $\begin{array}{l}\text { Pada saat melihat ceceran oli, respon saya selalu } \\
\text { ingin membersihkannya }\end{array}$ & 348 \\
\hline
\end{tabular}




\begin{tabular}{|c|c|c|}
\hline No & Item Pernyataan & Skor \\
\hline & Total Skor & 4.549 \\
\hline
\end{tabular}

Sumber: Hasil Pengolahan, 2019

Berdasarkan data pada tabel 4 tentang persepsi responden mengenai perilaku individu diperoleh skor sebesar 4.549. Hal ini menunjukan pernyataan karyawan yang terdapat pada PT. XXX Indonesia mengenai perilaku individu berada pada posisi setuju (Setuju $=4.386-5.418)$.

2. Persepsi Responden terhadap Kesehatan dan Keselamatan Kerja di PT. XXX Indonesia.

Tabel 4.2

Persepsi Responden terhadap Kesehatan dan Keselamatan Kerja

\begin{tabular}{|c|c|c|}
\hline No & Item Pernyataan & Skor \\
\hline 1 & $\begin{array}{l}\text { Saya bekerja sesuai dengan standar operasional } \\
\text { prosedur }\end{array}$ & 367 \\
\hline 2 & $\begin{array}{l}\text { Saya selalu mematuhi aturan kerja agar tidak terjadi } \\
\text { kecelakaan kerja }\end{array}$ & 372 \\
\hline 3 & $\begin{array}{l}\text { Saya selalu menggunakan alat pelindung diri pada saat } \\
\text { bekerja }\end{array}$ & 357 \\
\hline 4 & $\begin{array}{l}\text { Pemahaman tentang penggunaan alat keselamatan dan } \\
\text { kesehatan kerja perlu diberikan kepada setiap } \\
\text { karyawan }\end{array}$ & 385 \\
\hline 5 & $\begin{array}{l}\text { Perusahaan selalu memberikan edukasi tentang } \\
\text { pentingnya pemakaian alat keselamatan dan kesehatan } \\
\text { kerja }\end{array}$ & 365 \\
\hline 6 & $\begin{array}{l}\text { Perusahaan memberikan pendidikan tentang } \\
\text { keselamatan dan kesehatan kerja (K3) kepada setiap } \\
\text { karyawan }\end{array}$ & 361 \\
\hline 7 & $\begin{array}{l}\text { Perusahaan memberikan pelatihan tentang keselamatan } \\
\text { dan kesehatan kerja (K3) kepada setiap karyawan }\end{array}$ & 358 \\
\hline 8 & $\begin{array}{l}\text { Perusahaan melakukan pemeriksaan kesehatan } \\
\text { karyawan secara periodik }\end{array}$ & 381 \\
\hline 9 & $\begin{array}{l}\text { Aturan kerja sudah terpasang rapih dan jelas diarea } \\
\text { tempat kerja }\end{array}$ & 346 \\
\hline 10 & $\begin{array}{l}\text { Perusahaan memberikan jaminan keselamatan kerja } \\
\text { kepada para pekerja }\end{array}$ & 383 \\
\hline 11 & $\begin{array}{l}\text { Perusahaan memberikan jaminan kesehatan kerja } \\
\text { kepada para pekerja }\end{array}$ & 386 \\
\hline 12 & $\begin{array}{l}\text { Alat pemadam api ringan (APAR) sudah tersedia } \\
\text { diarea tempat kerja saya }\end{array}$ & 377 \\
\hline
\end{tabular}




\begin{tabular}{|c|l|c|}
\hline No & \multicolumn{1}{|c|}{ Item Pernyataan } & Skor \\
\hline 13 & $\begin{array}{l}\text { Fasilitas alat pelindung diri yang disediakan } \\
\text { perusahaan sudah memadai }\end{array}$ & 347 \\
\hline 14 & $\begin{array}{l}\text { Perusahaan menyediakan obat pertolongan pertama } \\
\text { pada kecelakaan (P3K) diarea tempat kerja }\end{array}$ & 339 \\
\hline 15 & Tempat air minum bersih tersedia diarea tempat kerja & 331 \\
\hline & \multicolumn{1}{|c|}{ Jumlah } & 5.455 \\
\hline
\end{tabular}

Sumber: Hasil Pengolahan, 2019

Berdasarkan data pada tabel 5 tentang persepsi responden mengenai kesehatan dan keselamatan kerja diperoleh skor sebesar 4.455. Hal ini menunjukan pernyataan karyawan yang terdapat pada PT. XXX Indonesia mengenai kesehatan dan keselamatan kerja berada pada posisi sangat setuju (Sangat Setuju $=4.418-6.450)$.

3. Analisis Korelasi dan Koefisien Determinasi

Tabel 4.7

Hasil Analisis Korelasi dan Koefisien Determinasi

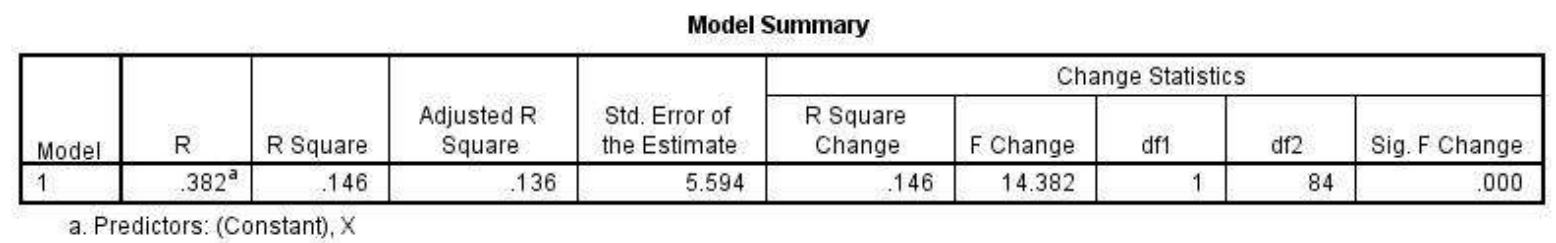

Sumber: Hasil Pengolahan, 2019

Berdasarkan data pada tabel tersebut diperoleh nilai korelasi $(\mathrm{R})$ sebesar 0,382, hal tersebut menunjukan terdapat hubungan positif antara perilaku individu dengan kesehatan dan keselamatan kerja sebesar 0,382. Nilai hubungan tersebut berada pada posisi rendah (Rendah $=0,200-0,399$ ). Nilai koefisien determinasi pengaruh perilaku individu terhadap kesehatan dan keselamatan kerja ditunjukan pada kolom R Square sebesar 0,146 (14,60\%), sedangkan sisanya sebesar $85,40 \%$ dipengaruhi oleh factor lain yang tidak diteliti.

\section{Pembahasan}

1. Hubungan antara Perilaku Individu dengan Kesehatan dan Keselamatan Kerja di PT. XXX Indonesia 
Hasil analisis koefisien korelasi antara perilaku individu dengan kesehatan dan keselamatan kerja diperoleh nilai sebesar 0,382 $(r \neq 0)$ dengan tingkat signifikansi sebesar 0,000, hal ini menunjukan bahwa terdapat hubungan positif rendah antara perilaku individu dengan kesehatan dan keselamatan kerja.

2. Pengaruh Perilaku Individu terhadap Kesehatan dan Keselamatan Kerja di PT. XXX Indonesia

Hasil analisis koefisien determinasi perilaku individu terhadap kesehatan dan keselamatan kerja diperoleh nilai sebesar 0,146 dengan tingkat signifikansi sebesar 0,000. Hal ini menunjukan bahwa terdapat pengaruh perilaku individu terhadap kesehatan dan keselamatan kerja sebesar 14,60\% dan sisanya sebesar $85,40 \%$ dipengaruhi oleh factor lain yang tidak diteliti.

\section{KESIMPULAN DAN IMPLIKASI}

Kesimpulan dari penelitian mengenai pengaruh perilaku individu terhadap kesehatan dan keselamatan kerja di PT. XXX Indonesia adalah sebagai berikut:

1. Perilaku individu / karyawan di PT. XXX Indonesia pada saat bekerja secara umum bekerja dengan baik. Keadaan ini ditunjukan dari persepsi karyawan pada hasil jawaban kuisioner tentang perilaku individu yang secara umum berada pada rentang setuju.

2. Pelaksanaan kesehatan dan keselamatan kerja di PT. XXX Indonesia secara umum sangat baik. Keadaan ini ditunjukan dari persepsi karyawan pada hasil jawaban kuisioner tentang kesehatan dan keselamatan kerja yang secara umum berada pada rentang sangat setuju.

3. Perilaku individu berpengaruh positif rendah terhadap pelaksanaan kesehatan dan keselamatan kerja di PT. XXX Indonesia. Keadaan ini ditunjukan dengan nilai signifikansi lebih kecil dari $\alpha$ (alpha).

\section{DAFTAR PUSTAKA}

A.A Anwar Prabu Mangkunegara, 2013. Manajemen Sumber Daya Manusia. Bandung: PT. Remaja Rosdakarya.

Brauer, R.L. 1990. Safety and Health for Engineer. New York: Van Nostrand Reinhold. 
Budiono Sugeng, R.M.S Jusuf, Andriana Pusparini. 2003. Bunga Rampai Hiperkes dan Keselamatan Kerja. Semarang: Badan Penerbit Universitas Diponegoro.

Codreanu, Aura. 2010. Organizational Change: A Matter Of Individual and Group Behavior Transformation, (Online), Vol 1, No. 1.

Daryanto. 2003. Dasar-dasar Teknik Mesin. Jakarta: PT. Bhineka Cipta Jakarta.

Ghozali, Imam. 2011. Aplikasi Analisis Multivariate Dengan Program SPSS. Semarang: Badan Penerbit Universitas Diponegoro.

Griffin, Jill (2002) dialih bahasakan oleh Dwi Kartini Yahya. 2002 “Customer Loyalty How to Earn it, How to Keep it, Lexington Books. Singapore.

Hamid, Abdul. 2010. Panduan Penulisan Skripsi. Cetakan kesatu. FEIS UIN Press: Jakarta.

Hanggraeni, Dewi. 2012. Manajemen Sumber Daya Manusia. Jakarta: Fakultas Ekonomi UI.

Hasibuan, Malaya S.P. 2011. Manajemen Sumber Daya Manusia. Jakarta: Bumi Aksara.

Hasibuan, Malayu S.P. 2016. Manajemen Sumber Daya Manusia. Edisi Revisi. Jakarta: Penerbit PT. Bumi Aksara.

Hurriyati Ratih, Dr., M.Si. 2012. Bauran Pemasaran dan Loyalitas Konsumen. Jakarta: Alfabeta CV.

Ibrahim Jati Kusuma dan Ismi Darmastuti. 2010. Pelaksanaan Program Keselamatan dan Kesehatan Kerja Karyawan PT. Bitratex Industries Semarang.

Ike Rachmawati Kusdyah. 2008. Manajemen Sumber Daya Manusia. Yogyakarta: ANDI.

Kuswana, WS. 2014. Ergonomi Dan Kesehatan dan Keselamatan Kerja. Bandung: PT. Remaja Rosdakarya.

Linggasari. 2008. Faktor-Faktor yang Mempengaruhi Perilaku. FKMUI.

Ravianto J. 1985. Produktivitas dan Manusia Indonesia. Jakarta. SIUP.

Riduwan. 2012. Metode \& Teknik Menyusun Proposal Penelitian. Bandung: Alfabeta.

Rivai, Veithzal. 2011. Manajemen Sumber Daya Manusia untuk Perusahaan: dari Teori ke Praktik. Jakarta: Raja Grafindo Persada.

Robbins, Stephen P. 2010. Perilaku Organisasi Edisi Bahasa Indonesia. Terjemahan Benyamin Molan. Jakarta: PT. Indeks. Kelompok Gramedia.

Santoso. 2005. Teknologi Pengolahan Kedelai (Teori Dan Praktek). Malang: Fakultas Pertanian Universitas Widyagama.

Sedarmayanti. 2011. Membangun dan Mengembangkan Kepemimpinan serta Meningkatkan Kinerja untuk Meraih Keberhasilan. Bandung: Refika Aditama.

Sedarmayanti. 2013. Manajemen Sumber Daya Manusia. Bandung: Refika Aditama.

Sedarmayanti. 2017. Perencanaan dan Pengembangan Sumber Daya Manusia. Bandung: Refika Aditama.

Silalahi, Ulber. 2011. Asas-Asas Manajemen. Bandung: Refika Aditama. Silalahi, Ulber. 2013. Asas-Asas Manajemen. Cetakan Kedua. PT. Refika Aditama. Bandung. 
Sinambela, Lijan Poltak. 2018. Manajemen Sumber Daya Manusia. Jakarta: Sinar Grafika Offset.

Sucipto, Cecep. 2014. Keselamatan dan Kesehatan Kerja. Gosyen. Publishing. Yogyakarta.

Sugiyono. 2012. Metode Penelitian Kuantitatif Kualitatif dan R\&D. Bandung: Alfabeta.

Sugiyono. 2018. Metode Penelitian Manajemen. Bandung: Alfabeta.

Sutrisno. 2012. Manajemen Keuangan Teori, Konsep dan Aplikasi. Yogyakarta: EKONISIA.

Thoha, Miftah. 2011. Perilaku Organisasi: Konsep Dasar dan Aplikasinya. Jakarta: PT. Raja Grafindo Persada.

Usman, Husaini. 2011. Manajemen, Teori, Praktek, dan Riset Pendidikan. Jakarta: PT. Bumi Aksara.

Wibowo. 2008. Manajemen Kinerja. Jakarta: Rajagrafindo Persada.

Wignjosoebroto, Sritomo. 2003. Ergonomi: Studi Gerak dan Waktu. Surabaya: Guna Widya.

Winarsunu, Tulus. (2008). Psikologi Keselamatan Kerja. Yogyakarta: UMM Press.

Febrian Dwi Rahadi, Hemy Heryati Anward, dan Silvia Kristanti Tri Febriana. 2013. Hubungan Antara Persepsi Lingkungan Kerja Fisik Dengan Perilaku Keselamatan Karyawan. Jurnal Ecopsy Volume 1. Nomor 1. Desember 2013 hal 19.

Mu'amalla, Khurry. 2015. Pengaruh perilaku karyawan terhadap penerapan norma Keselamatan dan Kesehatan Kerja (K3) di Area Penambangan Batubara Bawah Tanah PT. Nusa Alam Lestari Sawahlunto Sumatera Barat. Jurnal Bina Tambang Vol 2. No 1, 2015 hal. 9.

Putri, Ridha. Machasin, dan Chairul Amsal. 2015..Pengaruh Pengawasan, Lingkungan Kerja dan Disiplin Terhadap Keselamatan dan Kesehatan Kerja PT. Indah Kiat Pulp and Paper Kecamatan Tualang Kabupaten Siak. JOM Fekon Vol. 2 No.1 Februari 2015 hal. 12.

Wiraandika, Gatra. 2018. Pengaruh Pengawasan, Disiplin dan Lingkungan Kerja Terhadap Keselamatan dan Kesehatan Kerja Karyawan pada PT. Bumi Mulia Perkasa Dumai. Jurnal Tepak Manajemen Bisnis Vol. X. No. 1. Januari 2018 hal. 61.

Zhu, Yanhan. 2013. Individual Behavior: In-role and Extra-role, (Online), Vol 4, No.1. 